\title{
A Cutting Type Porthole Die Structure for Semi-hollow Al-Profiles
}

\author{
Peng Yun ${ }^{1,}$, Rurong Deng ${ }^{2, b}$ \\ 1,2 Guangzhou Vocational College of Science and Technology, Guangzhou, 510550, China \\ aemail:SQF6410@163.com, bemail:441752102@qq.com
}

\begin{abstract}
Key words: Aluminum profiles, semi-hollow, split type, hollow die, structure
Abstract. A new cutting type structure was presented. The split way for the new structure and the choice of relevant parameters were described, the lap jointing type to form the male die and female die a complete tongue, the design of portholes and the welding chamber and the bearing were included. And the results of use were analyzed and compared with the new structure and the traditional solid die structure and the cover type hollow die structure. It were shown that the new structure has obvious advantages, it can change the structure of tongue and reduce the ratio of tongue. This is a kind of die structure which is worth promoting. It expanded the range of choices as a die structure for the semi-hollow aluminum profiles and has very strong pertinence. The aim is to extend the experience and to provide reliable and valid reference data to the designers.
\end{abstract}

\section{Introduction}

With the continuous development and progress of modern processing technology, aluminum alloy profile products have been widely used, more and more varieties and specifications. In these types and various specifications of aluminum products, past experience is, according to their structural characteristics, the products can be summarized as hollow sections and solid profiles (non hollow sections) two types. These two types of materials are produced by the conventional porthole die and the solid die. But in practice, there are a considerable part of solid profile which can not be used in the production of solid die. Because these profiles have a long cantilever, its tongue is relatively large, the profiles are called as semi hollow section. If the traditional solid die or solid flow guide die structure is used for production of semi-hollow profiles, its die strength will be insufficient, the cantilevers are easily broken and collapsed, and the die will appear a phenomenon of early retirement, the die is not up to the normal life. In recent years, the demand for the semi hollow section of the industrial field is increasing, the die design of the semi hollow section is more difficult, its key is the strength of the die. Therefore, it is an urgent need for special structure for this kind of profile. Through practical examples, a new structure named cutting type special for the semi hollow Al-profiles will be introduced, it has characteristics of wide application range and easy processing.

\section{Raising of the Cutting Type Die Structure}

The cutting type porthole die structure is that the cantilever of the semi-hollow section is cut in a suitable position of dangerous section, the cantilever is divided into two parts, a hollow cavity is imagined, but the profile wall thickness of the hollow cavity in cutting is zero. Among them, a part is designed as a core of male die of porthole die, another part still remains in the original cantilever, the shape of a closed completely hollow part is formed as the die cavity of the female die. When the male die and the female die are combined, the core of the male die and the die hole of female die will joint in the part of cutting, a complete integrity of cantilever will reform. This form is exactly same as that of a common porthole die. Therefore, the structure has the characteristics of simple processing and high die life.

For the cutting type structure, the choice of cantilever's cutting position, that is, the choice of bonding plane of jointing the male die and female die is the key. For the profile shown in Figure 1, its cut position distance to be chose away from the risk of the root is $6.5 \mathrm{~mm}$, as shown in figure 2 . 


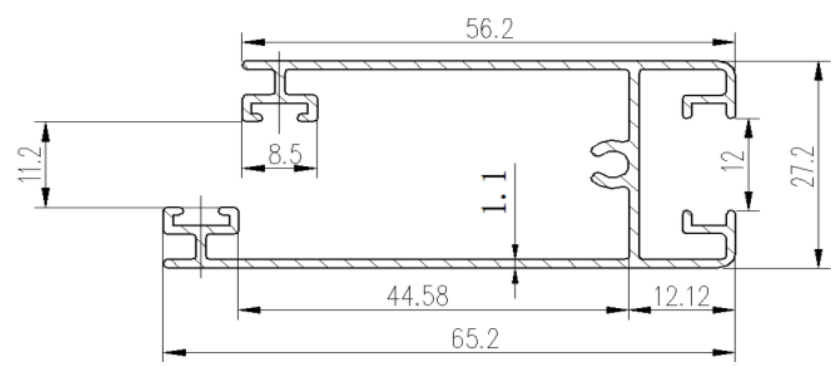

Fig.1 The signal of profile section

To be explained, and not all of the dangerous section of the profile are suitable for the use of the cutting type porthole die, The cutting line is suitable for the straight line. In principle, we should consider the following points:

(1)when the cantilever is divided into two parts, the part which left in the female die does not generate a new dangerous cantilever section. In addition, if the new cantilever can not be avoided, it should be possible to ensure that the width of the newly formed cantilever is at least $5 \mathrm{~mm}$, or a reference to the allowable value of tongue ratio for the semi hollow section.

(2)The part which is divided into the core does not appear to be the boss or the groove as far as possible in the cutting plane, This is conducive to the supply and the formation of metal.

(3)It is easy to process for the die.

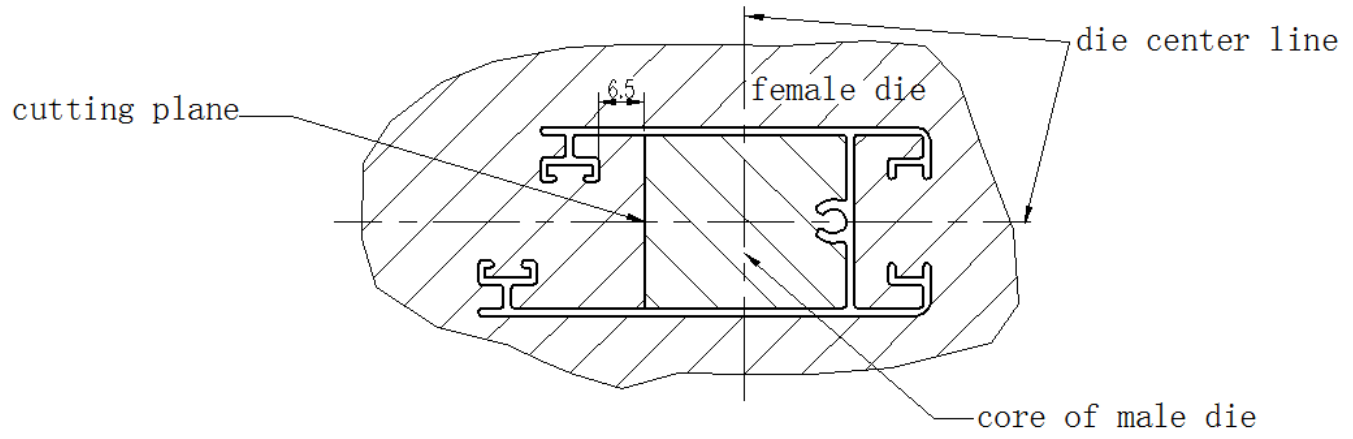

Fig.2 The signal of split way for the tongue

\section{The Lap Jointing Type of Female Die and Male Die}

When the cantilever is divided into two parts which can be left in male die and the female die respectively, when the two parts are combined in a die, it is very important to reform a complete cantilever in any way. After many years of exploration, two kinds of reliable and feasible structure are obtained for the size of the area of the cantilever, which are the vertical plane structure and the oblique plane joint structure.

3.1 The Vertical Plane Jointing Structure. The vertical plane jointing structure is that the planes of male die and female die are vertical plane in the division place, they are combined in the division place by the way of a vertical plane, as shown in Figure 3.

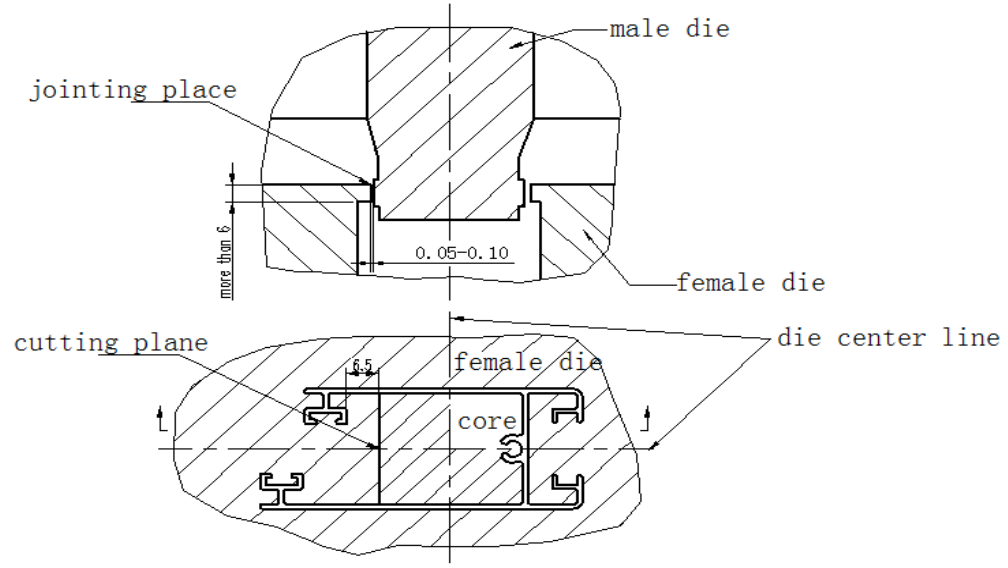

Fig.3 The lap jointing type with a vertical plane 
Using the vertical plane jointing structure, We must pay attention to the following points:

(1)In the arrangement of the feeder ports, the feeder ports are not arranged at the corresponding cutting positions of the cantilever as far as possible, so as to avoid the direct impact of metal on the jointing plane during the extrusion, the metal does not enter the bonding gap and a additional shape is formed, as shown in figure 4.

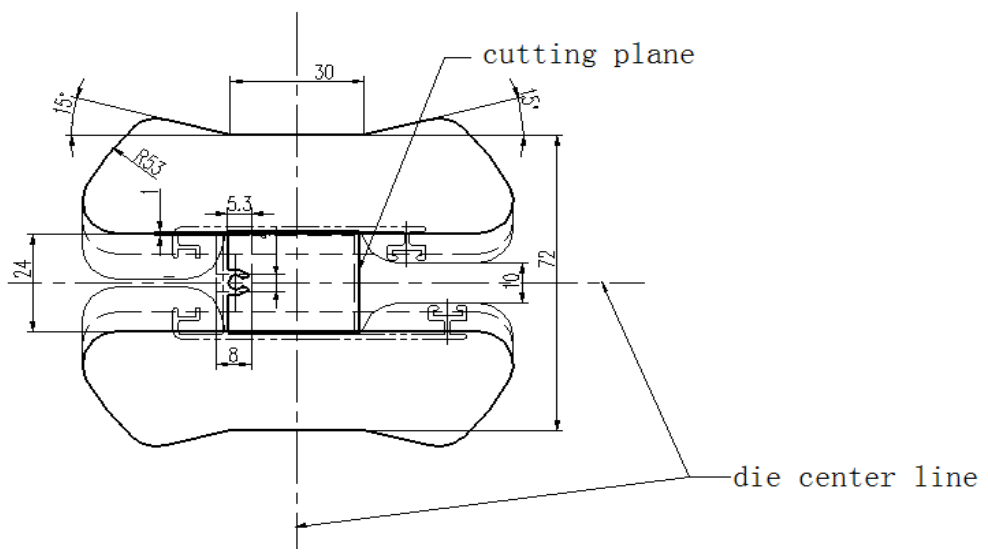

Fig.4 The signal of arrangement for feeder ports

(2)The feeder ratio of ports area should not be too small, it is desirable to equate extrusion ratio of 30 to 40 percent.

(3) The corner among the core and the die hole shall be sharp, and shall not be rounded. Otherwise, the metal will be formed in the joint plane and the profile will appear a raised wire or convex surface.

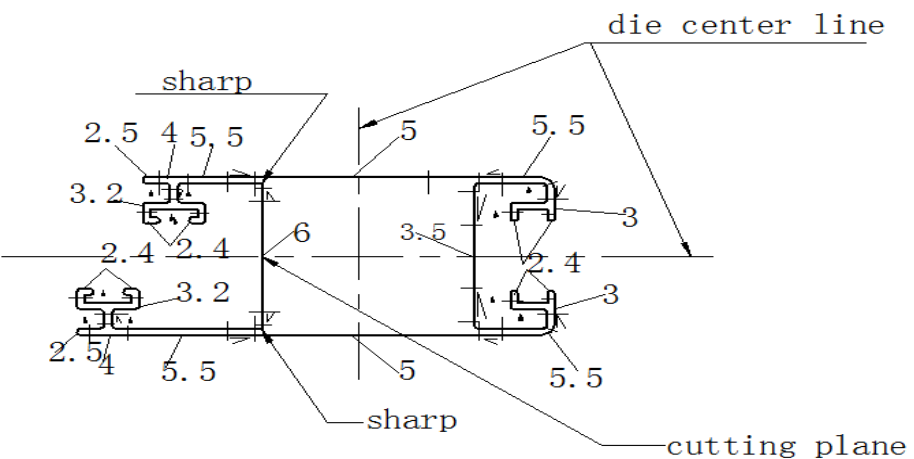

Fig.5 The signal of bearing with vertical plane

In the jointing plane of the female die, it can have a choice of the bearing greater than $6 \mathrm{~mm}$ and a die relief of under-cut $1.5 \mathrm{~mm}$, after grinding and polishing of baring, it will be easier to ensure the clearance value, or not have the choice of the bearing and die relief. The allowed clearance values must be processed in the the core of male die, the desirable clearance value is $0.05 \mathrm{~mm}$ to $0.10 \mathrm{~mm}$. And the bearing in the female die can be select in conventional selection, as shown in figure 5 .

When the structure is used, it is easy for the die to process. But the disadvantage is that the die will collide and be damaged easily in the process of assembling. Although the fitting clearance is theoretically zero, it is impossible in practice. At the same time, the gap of the joint position is zero in theory, but it is impossible to achieve in practice. The gap must be controlled in the range of $0.05 \mathrm{~mm}$ to $0.10 \mathrm{~mm}$, if it is too small, a collision will occur, too large, in the extrusion, the profile will appear a raised wire or convex surface, which will affect the quality of the profile. Therefore, with a requirement of no raised wire or convex surface, the structure with a vertical plane should not be used.

3.2 The Oblique Plane Joint Structure. The oblique plane jointing structure is that the planes of male die and female die are oblique plane in the division place, they are combined in the division place by the way of a oblique plane, as shown in Figure 6. 


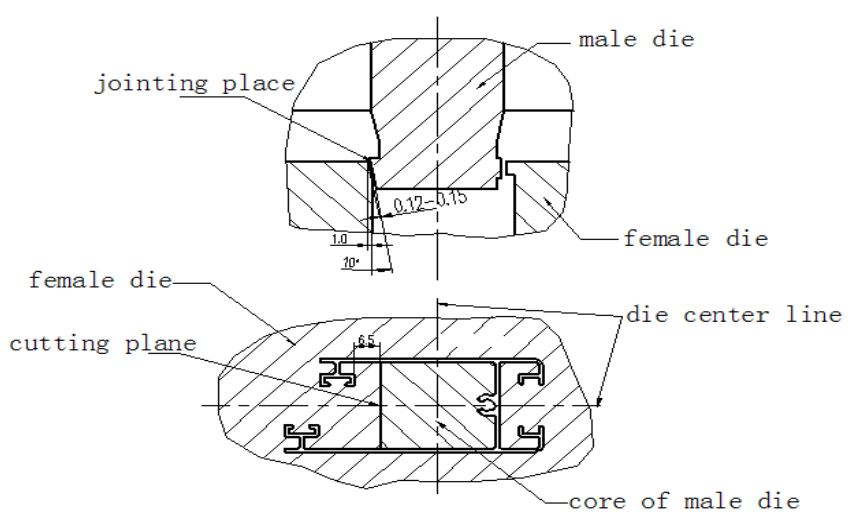

Fig.6 The lap jointing type with oblique plane

Using the oblique plane jointing structure, We must pay attention to the following points:

(1)In the arrangement of the feeder ports, the layout is used same as the vertical.

(2)The oblique jointing plane is used with 10 degree angular plane, its width is $1.0 \mathrm{~mm}$ to $2.0 \mathrm{~mm}$. In the oblique jointing place, it may not have the choice of the bearing and the process of die relief so as to avoid the collision .Similarly, the corners of jointing plane must be sharp.The selection of the bearing is carried out according to the principle of the design of porthole die, as shown in Figure 7.

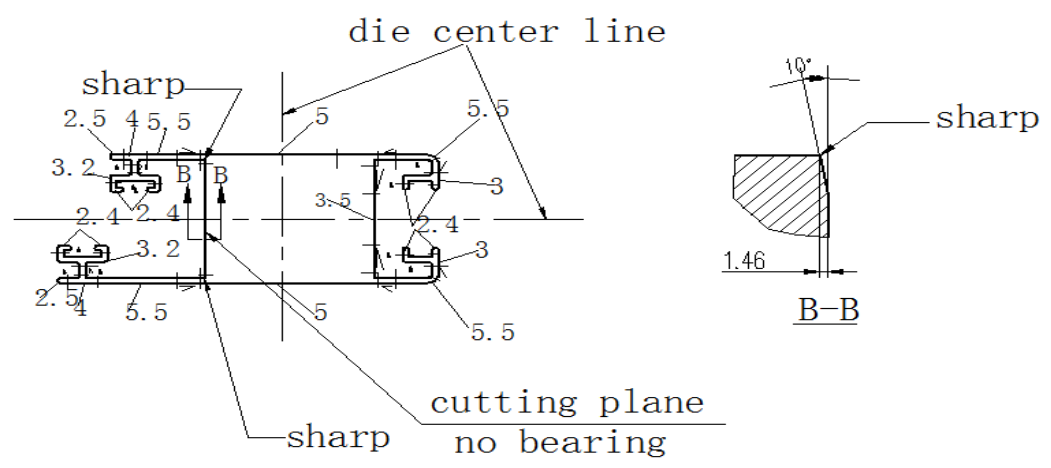

Fig.6 The signal of bearing with oblique plane

(3)The strength of male die must be enough to avoid the bridge bend downward and give a impact on the jointing oblique plane.

In this way, it overcomes the shortcomings of the vertical jointing, the direction of metal flow and the jointing plane is formed into an angle, the metal will be cut so that the phenomenon of raised wire and convex surface will disappear.

\section{The Analysis and Comparison}

4.1The Analysis of the Structure. Through the above examples, it can be known that the jointing plane of the vertical jointing plane structure is parallel to the extrusion direction. Therefore, the clearance value of control is the key. In addition, because of the metal friction, the corner of jointing plane will wear, when the die is used for a period of time, the clearance will become bigger more and more, so that the profiles will appear raised wire or convex surface and influence the quality.Therefore. when the surface quality has a requirement of high quality,the structure should not be used .

For the oblique jointing plane structure, the key is that the strength must be sufficient. Otherwise, the bridge will bend downward to impact the cantilever. It can be seen that the vertical plane structure is suitable for the large area of the cantilever, and the oblique plane structure is suitable for 
the small size of the cantilever.

4.2 The Extrusion Results Comparison. According to the extrusion tracking for the profile shown in figure 1, the traditional solid and the covering type of the porthole die structure and the cutting type structure were used, the results of the comparison are shown in table 1 . The results show that the cutting type structure has the obvious advantage, its die life is the longest.

Table1 The comparison of die structure and extrusion results

\begin{tabular}{|c|c|c|c|c|c|c|c|}
\hline $\begin{array}{c}\text { Die } \\
\text { structure }\end{array}$ & $\begin{array}{c}\text { Die } \\
\text { life } \\
\text { (tons) }\end{array}$ & $\begin{array}{c}\text { Wall } \\
\text { thickness } \\
\text { deviation }\end{array}$ & $\begin{array}{l}\text { Extrusion } \\
\text { Marks and } \\
\text { brightness }\end{array}$ & $\begin{array}{l}\text { Dimension } \\
\text { Precision } \\
\text { level }\end{array}$ & $\begin{array}{l}\text { Change of } \\
\text { Opening } \\
\text { size }\end{array}$ & $\begin{array}{l}\text { Processing } \\
\text { difficulty }\end{array}$ & $\begin{array}{c}\text { Die } \\
\text { material }\end{array}$ \\
\hline $\begin{array}{l}\text { Traditional } \\
\text { solid }\end{array}$ & $\begin{array}{l}\text { Less } \\
\text { than } \\
2\end{array}$ & obvious & deep, rough & general & big & Simple & $55.2 \mathrm{Kg}$ \\
\hline $\begin{array}{l}\text { covering } \\
\text { type }\end{array}$ & 8.6 & Not obvious & low, shining & high & medium & big & $62.3 \mathrm{Kg}$ \\
\hline $\begin{array}{l}\text { Cutting } \\
\text { type }\end{array}$ & $\begin{array}{l}\text { More } \\
\text { Than } \\
15.5\end{array}$ & No & low, shining & high & No & Simple & $35 \mathrm{Kg}$ \\
\hline
\end{tabular}

\section{Conclusions}

The cutting type porthole die special for the semi-hollow profiles, its key point is to change the structure of the cantilever and reduce the ratio of the cantilever's tongue, so as to improve the strength of the die. The results showed as follows:

(1) The cutting type structure, its key is to choose the reasonable cutting position of cantilever and the jointing type of male and female die. The jointing way has the vertical and oblique plane of two types.

(2) The cutting type porthole die structure, it changed the structure of the cantilever so that the risk of the cantilever section disappeared, it can greatly reduce the ratio of the cantilever tongue so that it can greatly improve the strength of the die.

(3) The results show that the cutting type structure has the obvious advantage. Comparing with the traditional solid and the covering type of the porthole die structure, its die life is the highest up to more than 15 tons, while the quality of the profile can be better guaranteed.

(4) The structure of the cutting type porthole die is more suitable for the semi hollow profiles.

(5) The cutting type porthole die structure, which has the characteristics of simple manufacture, short manufacturing cycle and low material consumption.

When the new structure is used, if the flow and characteristics of metal can be fully utilized, the design principle of the porthole die is more reasonably carried out, and the related parameters are optimized, the better results will be obtained. The new structure is worth of promotion.

\section{References:}

[1] LIU Jingan. Die design,manufacture,application and maintains for aluminum profiles extrusion[M].Beijing:Metallurgical Press, 1999:181 183.

[2] XIE Jianxie,LIU Jingan, Die design,manufacture,application and maintains for aluminum profiles extrusion[M].Beijing:Metallurgical Press,2012:133 138

[3] WANG Liwei.Optimization design of extrusion die for the bigger slenderness ratio half hollow aluminum profile[J].Die and Mould Manufacture,2011(4):61-64.

[4] YU Mingtao,LI Fuguo.Simulation extrusion process of the sketch hollow aluminum profile based on infinite volume method[J].Die and Technology, 2008(4):40-43. 
[5] SUN Xuemei,ZHAO Guoqun.Fake porthole extrusion die structure design and strength analysis for cantilever aluminum alloy profiles[J].Journal of Mechanical Engineering,2013, 49 (24) : $39 \sim 44$.

[6]KUANG Weihua,CHEN Biaobiao.Research on design and structure of extrusion die for cantilever aluminum profile [J].Hot Working Technology,2013,42(21):136-138.

[7]DENG Rurong,Huang,Xuemei.Design of the extrusion die of semi-hollow aluminum profile[J].Light Alloy Fabrication Technology,2015,43(4):51-54.

[8]Xu Yongli, Huang Shuangjian, Pang Zugao, et al.Failure analysis of extrusion die and optimization of heat treatment process for aluminum alloy circular tube [J]. Forging \& Stamping Technology, 2015, 40 (2) : 116-122. 